\title{
Renal cell carcinoma
}

\author{
Axel S. Merseburger ${ }^{1}$ Börje Ljungberg ${ }^{2} \cdot$ Axel Bex $^{3}$
}

Published online: 11 July 2016

(C) Springer-Verlag Berlin Heidelberg 2016

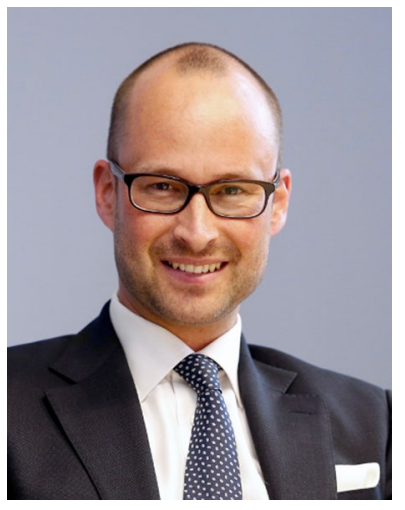

Axel S. Merseburger

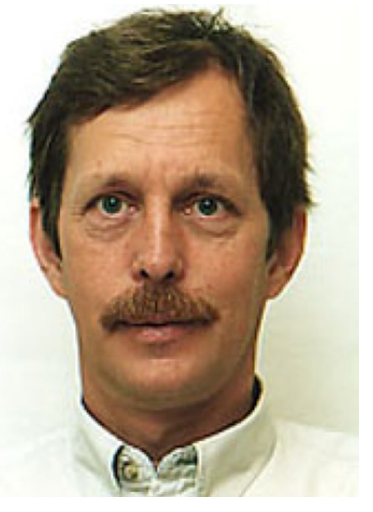

Börje Ljungberg

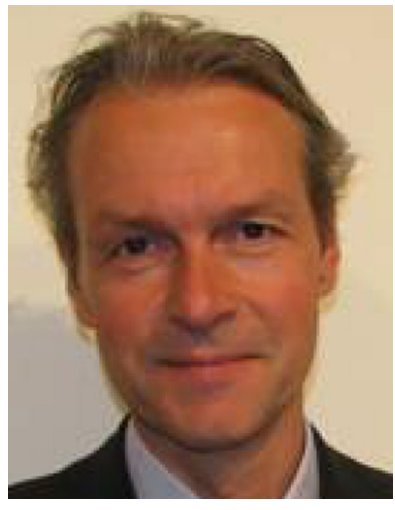

Axel Bex
The guest editors of this special issue, all members of the European Association of Urology Renal Cell Carcinoma (RCC) Guideline Panel, have been asked by the editorial board of the World Journal of Urology to collect and publish a series of articles on RCC which touch on topics for which high level of evidence recommendations are lacking

Axel S. Merseburger

axel.merseburger@uksh.de

http://www.urologie.uni-luebeck.de

1 Department of Urology, University Hospital SchleswigHolstein, Campus Lübeck, Ratzeburger Allee 160, 23538 Lübeck, Germany

2 Department of Surgical and Perioperative Sciences, Urology and Andrology, Umeå University, Umeå, Sweden

3 Department of Urology, The Netherlands Cancer Institute, Amsterdam, The Netherlands in the guidelines. We thank all authors to have followed our invitation and to have shared their professional inside information with us. As all articles have been peer-reviewed, we would also like to thank all reviewers for their valuable time, work, and suggestions.

Generally, adherence to guideline recommendations is poorly studied. Aben et al. [1] have focused on adherence to guideline recommendation for management of clinical T1 renal cancers in the Netherlands. In this populationbased study, the implications of national and international guidelines are well evaluated and provide insight on how adherence to guidelines could be compared across different health care systems in Europe. No recommendations can be given for targeted therapy to improve outcome after metastasectomy. This clinical scenario has been evaluated by Brehmer et al. [2] when presenting their data on resection of metastasis and local recurrences of RCC after 
presurgical targeted therapy. We hope to have drawn your interest in including some topics of our own groups [3-5] on comparison of prognostic risk models in patients with synchronous metastatic RCC treated in the era of targeted therapy and surgical options in metastatic disease as well as the probability of RCC recurrence in a Swedish populationbased study. Due to a lack of comparative data on different follow-up schedules, no clear recommendations for surveillance can be given in guidelines. We are therefore pleased to add to the Swedish data on recurrence further follow-up studies from Norway [6] and the Netherlands [4].

The guest editors of this issue of the World Journal of Urology are thankful to have the opportunity to draw attention to the third most frequent urological malignancy. We wish our readers an inspiring and interesting time reading the following articles on the latest controversies on renal cell carcinoma.

\section{Compliance with ethical standards}

Conflict of interest No conflicts of interest.

\section{References}

1. Aben KKH, Osanto S, Christina A, de Kaa H-v, Soetekouw PM, Stemkens D, Bex A (2016) Adherence to guideline recommendations for management of clinical T1 renal cancers in the Netherlands: a population-based study. World J Urol. doi:10.1007/ s00345-016-1841-3
2. Brehmer B, Kauffmann C, Blank C, Heidenreich A, Bex A (2016) Resection of metastasis and local recurrences of renal cell carcinoma after presurgical targeted therapy: probability of complete local control and outcome. World J Urol. doi:10.1007/ s00345-016-1865-8

3. Noe A, de Bruijn RE, Blank C, Horenblas S, Haanen J, Bex A (2016) Comparison of pre-treatment MSKCC and IMDC prognostic risk models in patients with synchronous metastatic renal cell carcinoma treated in the era of targeted therapy. World $\mathrm{J}$ Urol. doi:10.1007/s00345-016-1769-7

4. Kuijpers YAM, Meijer RP, Jonges GN, de Jong J, Bosch JLHR, Horenblas S, Bex A (2016) Potentially curable recurrent disease after surgically managed non-metastatic renal cell carcinoma in low-, intermediate and high-risk patients. World J Urol. doi:10.1007/s00345-016-1822-6

5. Dabestani S, Thorstenson A, Lindblad P, Harmenberg U, Ljungberg B, Lundstam S (2016) Renal cell carcinoma recurrences and metastases in primary non-metastatic patients: a populationbased study. World J Urol. doi:10.1007/s00345-016-1773-y

6. Beisland C, Guðbrandsdottir G, Reisæter Lars A R, Bostad L, Hjelle KM (2016) A prospective risk-stratified follow-up programme for radically treated renal cell carcinoma patients: evaluation after eight years of clinical use. World J Urol. doi:10.1007/ s00345-016-1796-4 